\title{
(IN)FIDELIDADE FEMININA: ENTRE A FANTASIA \\ E A REALIDADE
}

\author{
Marion Arent*
}

\section{Resumo}

Este artigo investiga a (in)fidelidade conjugal feminina em um "Clube de Mulheres" na cidade do Rio de Janeiro. Dados revelam desigualdades de gênero em relação à infidelidade conjugal. Alguns alicerces da dominação masculina, como a heteronomia e a vitimização, persistem entre as informantes. Para a maioria delas, querer não equivale a poder trair, como atestam as diversas estratégias de ocultação e as "justificativas” que apresentam à traição como reação à rotina do casamento e/ou à suposta infidelidade do parceiro. Traidores e/ou traídos, os homens, enquanto categoria sociossexuada, são dominantes. A ruptura com certos preceitos normativos do gênero feminino é fonte de prazer, mas também de culpa. Valores tradicionais, como fidelidade, segurança e estabilidade aparecem lado a lado com outros considerados modernos, como independência, autonomia e privacidade.

Palavras-chave: (in)fidelidade; conjugalidade; gênero; sexualidade; clube de mulheres.

\section{Abstract}

FEMALE (IN)FIDELITY: BETWEEN FANTASY AND REALITY

This article investigates female marital infidelity in a "Women's Club" in Rio de Janeiro. Data show gender inequality regarding marital infidelity. Some male domination elements, such as heteronomy and victimization, remain among informants. For the majority of them, a wish to betray does not mean that they will be allowed to betray. Many women use hiding

* Psicóloga pela Universidade do Vale do Rio dos Sinos (UNISINOS); Mestre em Psicologia pela Pontifícia Universidade Católica do Rio Grande do Sul (PUCRS); Doutora em Saúde Coletiva pela Universidade do Estado do Rio de Janeiro (UERJ); Pós-doutoranda pela Universidade de Buenos Aires (UBA). 
strategies and "justifications" that show betrayal as a reaction to marriage routine andlor to a partner's supposed infidelity. Either traitors and/or betrayed, the men are dominant. A rupture with some normative female gender precepts is a pleasure source, but also brings about fault feelings. Traditional values, such as fidelity, security and stability appear side by side with others considered modern, such as independence, autonomy and privacy.

Keywords: (in)fidelity; conjugality; gender; sexuality; women's club.

\section{INTRODUÇÃO}

Este artigo, derivado da tese de doutorado defendida pela autora (Arent, 2007), tem como objetivo apresentar e discutir dados etnográficos acerca da (in)fidelidade conjugal feminina no plano da heteronormatividade. São enfocadas suas motivações, seja no que concerne "apenas" à fantasia da traição, seja na sua ocorrência de fato, bem como as estratégias colocadas em operação pelas informantes e seus sentimentos em relação a isso. A discussão se justifica pela atualidade e relevância do tema, atestadas pela efervescência de debates no mundo acadêmico brasileiro e internacional. As múltiplas facetas do fenômeno lhe conferem complexidade e demandam distintas abordagens. Optou-se por contemplar autores/as das Ciências Sociais, dentre eles alguns teóricos da pós-modernidade, como Anthony Giddens (1993) e Zygmunt Bauman (2004), considerando que as transformaçōes "operadas nas relações de gênero são elementos centrais do processo de modernização" (Matos, 2000: 44)1. De acordo com Heilborn, Cabral e Bozon (2006), "a opinião sobre fidelidade funciona como barômetro da moralidade desejável nas relaçôes afetivas. Trata-se de um tópico sensível para descrever a mentalidade de uma época ou geração" (Heilborn e cols., 2006: 212).

A (in)fidelidade conjugal encontra, no "líquido mundo moderno" referido por Bauman (2004: 46), condiçôes favoráveis à sua emergência, dado que este mundo "detesta tudo o que é sólido e durável, tudo que não se ajusta ao uso instantâneo" (idem). Nele "as coligações tendem a ser flutuantes, frágeis e flexíveis" (ibid.: 41), pois, "nos compromissos duradouros, a líquida razão moderna enxerga a opressão; no engajamento permanente percebe a dependência incapacitante" (ibid.: 65). Dentro deste contexto, Marlise Matos (2000) traz a fragmentação e a multiplicação das experiências e a crescente individualização dos gêneros, aspectos que fomentam transformaçōes na esfera da sociabilidade no mundo público e sobretudo no privado.

Este novo cenário social abre espaço para a realização bem-sucedida de um empreendimento de lazer noturno como o "Clube das Mulheres" $(\mathrm{CM})^{2}$, que con- 
siste em espetáculos de strip-tease masculino para plateias femininas. O local onde os dados desta pesquisa foram produzidos refere-se a uma boate situada no centro da cidade do Rio de Janeiro. Após tocar o "hino" da festa, como é anunciada a música It's raining men, os strippers, aqui denominados "sedutores", fazem performances individuais trajando fantasias, tais como Bandido, Mafioso, Malandro, Diabo, Sadomasoquista, Mecânico, Bombeiro, Gari, Executivo, Médico, Oficial das Forças Armadas, Policial Militar, Guarda-Costas, Lutador de Vale Tudo, Ninja, Árabe, Cigano, Noivo, Don Juan, Zorro e Fantasma da Ópera. Nestes shows eles dançam, tiram a roupa - sem mostrar os genitais - e encenam variadas posições sexuais com mulheres do público que manifestam explicitamente o desejo de serem "escolhidas" para subir ao palco, aspecto que diferencia este espetáculo de outros, nos quais a divisão palco/plateia é bem delimitada. Após o término do espetáculo, é permitida a presença do público masculino, quando então tem início uma festa dançante.

Nas "Noites do Beijo na Boca", evento que tem espaço sempre na última terça-feira de cada mês, a performance no palco inclui, obrigatoriamente, o beijo na boca entre cada sedutor e as mulheres que lá subirem. O beijo na boca está aqui destituído do apelo romântico que o representa como vetor de transmissão de afeto; veicula sensualidade, erotismo e desejo, mas não amor, segundo a distinção exposta por Bauman (2004): "o desejo não precisa ser instigado por nada mais do que a presença da alteridade" (Bauman, 2004: 23), é vontade de consumir e se autodestrói, pois sua realização coincide com a aniquilação do objeto; é um impulso centrípeto, ao contrário do amor, que é centrífugo e se autoperpetua.

\section{Metodologia}

O trabalho etnográfico demandou uma frequência regular ao CM durante quatro meses, perfazendo um total de vinte e quatro observações participantes, referentes ao contexto global (tanto o show quanto a festa que o sucede).

As entrevistas semiestruturadas, compostas de perguntas abertas, seguiram roteiros distintos para cada grupo de informantes: strippers, clientes de ambos os sexos, trabalhadores/as da casa e organizadores do evento, somando vinte e uma entrevistas individuais, além de várias - e produtivas - conversas informais travadas com todos os segmentos de informantes no decorrer do trabalho de campo.

$\mathrm{Na}$ totalidade das situações apresentei-me enquanto psicóloga/pesquisadora, buscando sempre a anuência e o consentimento dos/as informantes em participar da produção dos dados, bem como assegurando a total preservação do anonimato e do sigilo em cada etapa da pesquisa, aspecto reforçado pela garantia do uso irrestrito de codinomes. 


\section{APRESENTAÇÃO E DISCUSSÃO dOS RESULTADOS}

O fato de esta festa ocorrer no centro da cidade, em horário de happy-hour (a partir das 18 horas) e em dias de início de semana - às segundas, terças e quartasfeiras -, facilita a presença "anônima" de pessoas casadas ou com compromisso afetivo (namorado/a, noivo/a), gerando circunstâncias potencialmente favoráveis à emergência de episódios de infidelidade. Além disso, seu caráter controlado e regrado a legitima como um território adequado à fruição erótica feminina. As regras, ao contrário de anularem o desejo, o veiculam, possibilitando sua emergência contida no tempo e no espaço. Algumas mulheres transgridem determinadas normas tradicionalmente prescritas ao seu gênero e assim obtêm prazer, concretizado pelo confronto com uma possível situação de infidelidade, mais do que pelo - improvável - ato sexual per se. A transgressão, contrapartida das regras, é por si só uma fantasia, talvez a principal delas, porque gera e possibilita a emergência das demais. A partir daí se dá a fabricação do desejo que anima, com toda sua força, intensos momentos de lazer e prazer.

Uma moça alegou tais fatores para justificar a crença de que sua frequência ao CM passe despercebida de seu namorado, de modo que ela consegue aliar a diversão com as amigas à manutenção do relacionamento com ele. A jovem Janaína contou que trouxe uma colega que está vindo pela primeira vez ao $\mathrm{CM}$, e que esta garota mentiu ao namorado dizendo estar na academia de ginástica, motivo pelo qual logo após o término do show elas iriam embora, pois a amiga precisava trocar de roupas e chegar à academia antes do namorado. Já o namorado de Janaína sabe de suas idas ao CM, mas "ninguém gosta, né, aí hoje falei para ele que era uma festa de aniversário, para poder trazer ela, que ela queria vir" (ênfase nossa). O desejo de estar ali era, assim, projetado na amiga.

Querer e não poder, ou sequer poder querer, configura um elemento que aparece no discurso dos/as informantes como algo imanente ao feminino. O breve diálogo mantido com a frequentadora Sabrina ilustra isso: "Tu vens sozinha?", perguntou ela. Falei rapidamente da pesquisa e ela então disse, rindo: "A tese é desculpa para poder vir, né" (ênfase nossa), como se, caso contrário, eu não pudesse dar vazão a um suposto desejo de ali estar. Mesmo a assídua frequentadora Marília, cujo discurso calcado no ideário individualista moderno prioriza a autonomia ${ }^{3} \mathrm{e}$ traz a escolha pessoal como marca da distinção em relação às demais mulheres "sempre fui muito independente, eu faço o que eu quero, e lá eu posso fazer o que eu quero: frequentar a boate, ir ao palco e ter meu namorado, o que muita mulher não pode fazer; podem, mas fazem escondido", ou então, "ninguém paga minha entrada nem minha saída, eu consigo me sustentar, pago minhas contas" -, mente 
ao dizer ao namorado que não tem subido ao palco desde a época em que está comprometida com ele, atitude que atesta a limitação de sua autonomia em relação ao parceiro ${ }^{4}$. Afirma frequentar o local: "pelo show, com certeza, tanto que agora que estou namorando estou indo para ver o show e sair. Buscava um relacionamento lá e então acho que eu não tinha mais que querer ir [ao $\mathrm{CM}$ ], porque o que eu estava procurando eu encontrei. Isso me incomoda, acho que se eu estivesse completa eu não teria vontade de ir".

O posicionamento de Marília, graduada em História da Arte, reitera que "a maior escolarização é indicativa de um maior grau de reflexividade e propensão socialmente adquirida para a problematização" (Heilborn, Cabral e Bozon, 2006: $221)^{5}$. Sua fala demonstra ainda que, "quando os atores buscam dar coerência a suas experiências, são frequentemente levados a se referir a pares de significações potencialmente contraditórias" (Bozon, 2004a: 137), como liberdade e compromisso, ou autonomia e heteronomia.

Além de mentir, algumas mulheres desenvolvem habilidosas estratégias de ocultação da frequência ao CM diante dos companheiros, que supostamente as aguardariam em casa sem saber onde estavam. Logo ao chegar várias delas se maquiam, enquanto outras mudam de roupa no banheiro da boate, trocando as vestimentas usadas na vida laboral e/ou escolar por um visual mais provocativo e sensual, como minissaias e sandálias de salto alto, mais adequadas e "gramaticalmente coerentes com os gestos e o comportamento" (DaMatta, 1980: 47) colocados em operação nesta festa. Antes de partir, algumas têm o cuidado de lançar mão do demaquilante, como pude observar.

As tentativas de encobrimento dos sinais da passagem pelo CM, bem como do que acontece ali, seja no palco ou na festa pós-show, atestam a escassa autonomia que elas demonstram ter em relação às redes de controle social. Muitas não desejam e/ou não podem revelar publicamente sua frequência ao local, como expõe o fotógrafo Gabriel: "Quando eu chego num grupo para tirar foto a mulherada faz uma cara de assustada, aí eu brinco, nunca vou e tiro uma foto, para botar no site, de uma pessoa que não queira, posso estar denegrindo a imagem da pessoa, dependendo da situação". Em respeito ao direito de privacidade, ele jamais tira fotografias das mulheres no palco durante os espetáculos: "Como eu vou saber se posso tirar [fotos] ou não?”, indaga.

Parte da vivência de clandestinidade e de infidelidade experimentada por estas mulheres deriva de um acordo tácito cujo mote principal reside na ocultação do conteúdo e da forma daquilo que ocorre no palco até as 20:30 horas. Os homens que frequentam a casa após o espetáculo, bem como os companheiros destas mulheres, além de outros sujeitos que compõem seu meio familiar, profis- 
sional e/ou social, permanecem na ignorância parcial ou total. Algumas situações vividas no decorrer do trabalho de campo atestam isso.

A assídua frequentadora Vanessa indagou se meu namorado sabe que tenho ido regularmente ao $\mathrm{CM}$, ao que respondi afirmativamente. "Mas ele não sabe que você vai subir no palco, né?", disse ela, rindo em tom provocativo, já que havia me instigado a isso noutra ocasião. Noutra noite, ao se propor a me conceder uma entrevista, Vanessa forneceu seu número de telefone mediante a solicitação de que "se alguém atender, não fala do 'Clube das Mulheres', nem da boate, só fala que quer falar comigo, porque meus pais atendem meu celular". Ela demonstra separar nitidamente o espaço das relações familiares do lazer vivido na sociabilidade do CM.

Certa noite, Adriana, advogada que conheci no $\mathrm{CM}$, me reencontrou lá e disse ter telefonado para minha residência, a fim de saber se eu iria ao CM naquela noite, ressaltando o fato de não ter mencionado nada que revelasse a natureza do evento diante da pessoa que havia atendido à ligação (minha madrasta). Apenas perguntou-lhe se eu havia me dirigido ao centro da cidade para dar prosseguimento ao trabalho que venho realizando, ao que ela prontamente respondeu: "Ah, o 'Clube das Mulheres'? Ela já foi, está lá, sim!”.

Noutra noite ouvi uma voz feminina dirigida a mim: "Marion, você por aqui...!”. Era Alice, uma funcionária da universidade na qual estudo. Diante de minha reação de surpresa, e desconhecendo os motivos de minha presença no local, exclamou: "Não se preocupe, sou um túmulo, de mim ninguém saberá que eu te vi aqui!”.

Outro exemplo reside no caso de Vera, que aparenta ter cerca de cinquenta anos. Segundo sua amiga Raquel, Vera tem um "namorido" de vinte e quatro anos, que ela só permite visitá-la em sua casa aos finais de semana, "prestação de serviço, entende?", mas mesmo assim manteve um caso com o sedutor João durante um ano e meio. Vera não revelou este caso ao "namorido", nem a mim. Disse, em tom bastante formal, ter passado a frequentar o CM há cerca de um mês, sendo que esta seria sua segunda vez ali, e que veio em função de "um colega médico, que dança aqui", conhecido de seu "marido". Vera parece vivenciar aquilo que Bauman (2004) qualifica como "relacionamentos de bolso, do tipo de que se pode dispor quando necessário e depois tornar a guardar" (Bauman, 2004: 10), algo marcado pela disponibilidade e instantaneidade, pressupondo uma "insustentável leveza do sexo” (Bauman, 2004: 64), oposto ao que Giddens (1993) entende por relacionamento: "um vínculo emocional próximo e continuado com outra pessoa” (Giddens, 1993: 68). 
Uma exceção figura no depoimento da frequentadora Bianca. Quando seu namorado lhe perguntou "O que é que tem nessa boate que você sai radiante de lá?", ela confessou, orgulhosa: "Eu tive a coragem de dizer, e falei para ele fazer tudo isso comigo na cama!". O resultado, segundo ela, foi "perfeito".

A curiosidade manifesta pelo parceiro de Bianca não é exclusividade dele. $\mathrm{O}$ cliente Adriano, namorado de Marília, imagina que "rola tudo ali só entre mulheres, o homem não sabe. As mulheres falam que os homens são maravilhosos, que são isso ou aquilo".

A aura de mistério parece contribuir para incrementar a vontade de frequentar o CM, como expõe Marília: "Os homens não sabem o que acontece lá, pensam mil coisas, que os homens ficam nus, e ficam 'bolados' que a mulher deles está lá”.

A questão da (in)fidelidade está presente também nas letras dos funks que compõem a trilha sonora dos espetáculos, como ilustram os seguintes trechos: "É melhor ser de várias mulheres do que minha mulher ser de todo mundo!"; "Não tem essa de falar que é fiel, fala que ele é 'meu', amante fala é 'nosso'!"; "O marido é meu!"; “Aquela 'mina' ali é minha, e eu sou ciumento!”. O funk intitulado "Clube das Mulheres", que o organizador Fernando qualifica como o "hino das casadas", traz esta temática de modo evidente:

No Clube das Mulheres, a gente zoa,

Dinheiro na sunguinha e eu tô rindo à-toa,

Os cara saradinho, ah, eu tô rindo,

Eu vou chifrar o meu marido!

Eles são engraçado, né?

Vão pra Mimosa, chegam em casa duro e cheio de ziquizira no pintinho!

Se eles podem, nós podemos também!

A fala em tom provocativo de Fernando, ao microfone, acompanhando este funk, é ilustrativa: "Tem alguma casada aqui?". O sentido da letra fica ainda mais explícito quando sabemos ser derivado de uma reação feminina ao funk "Adultério"

$\mathrm{Na}$ Quatro por Quatro, a gente zoa

Whisky, Red Bull, tanta mulher boa

[...] o bagulho tá sério, vai rolá um adultério!

A mulher aparece como um ser cuja ação é reativa à conduta masculina: "se eles podem, nós podemos também”. A infidelidade é tida como prerrogativa deles. Querer, para as mulheres, não equivale a poder, como costuma acontecer no caso dos homens ${ }^{7}$. Apesar da aparente ruptura com alguns preceitos normativos 
de gênero, a mulher não é vista neste plano nem por si própria, como um sujeito autônomo, pois sua conduta é regida pela heteronomia. Dentro de uma postura de vitimização, a culpa pelas atitudes femininas fica depositada no parceiro e na relação com ele mantida, configurando uma reação, um contraponto. Daí deriva a motivação de muitas delas para frequentar o CM. Como ponderou a promoter Mirian: "as mulheres ficaram tão trancadas em casa, os homens iam para o puteiro, não que aqui seja um, mas... Os direitos não são iguais?”, indaga, sinalizando a "difusão, ainda que parcial, de um ideário de maior simetria nas relaçóes de gênero" (Heilborn, Cabral e Bozon, 2006: 221), resultado da modernização dos costumes. Tal simetria seria operada "em termos de uma indiferenciação valorativa em que as distinçôes estatutárias entre os sexos cedem lugar a um ideal de paridade" (ibid.: 117). No universo aqui pesquisado, a paridade não vigora. Prevalece a desigualdade de gênero em relação à vivência, real ou fantasiada, da infidelidade conjugal. Até traídos os homens, enquanto categoria sociossexuada, são dominantes. Elas continuam sob o jugo da dominação masculina, mesmo quando parecem romper com ela.

A postura feminina diante da presumida infidelidade masculina traz consigo um ganho secundário. Agindo assim, elas aliviam o sentimento de culpa que surge mesmo quando a traição é exercida apenas no plano da fantasia, ou de modo parcial (mediante a troca de beijos na boca e de carícias, sem a consumação do ato sexual, por exemplo). Afinal, a culpa é do parceiro, potencialmente traidor.

A percepção da infidelidade feminina como fenômeno derivado da contrapartida masculina e tendo um sentido orientado pelo desejo de vingança é corroborada pela pesquisa conduzida por Mirian Goldenberg (2006) junto às camadas médias urbanas cariocas. Segundo a autora, as mulheres não se assumem como sujeitos da traição, dado que não agem autonomamente nestas circunstâncias, mas sim evocam a culpabilização do parceiro infiel e/ou pouco dedicado como motivação para um ato que eles, ao contrário, costumam explicar como fruto de um mix de elementos: "atração física, vontade, tesão, oportunidade, galinhagem, testicocefalia, natureza masculina, instinto" (Goldenberg, 2006: 345).

O discurso de vitimização é frequente, sustentado pela justificativa da rotina enfadonha. Luciano, um dos organizadores do CM, fez o seguinte comentário: "Estranho as mulheres que vêm aqui duas mil vezes e ainda ficam, entre aspas, excitadas, e se não sobem no palco não estão satisfeitas. Isso é muito problema de relação [conjugal]". A frequentadora Adriana também evocou a culpabilização das relações maritais:

Muitas mulheres vêm aqui por carência, muitas se dizem casadas de anos, ou de pouco tempo. É essa diferença, porque o "homem doméstico" fica mecânico, 
não valoriza, só faz cobrar, mais cobra do que dá, não nota a mulher na essência dela, feminina, nos caprichos, fazer elogios, dar um beijo na hora inesperada, e aqui ela vai realizar essa fantasia, e vice-versa, os homens também vão nesse tipo de casa em busca dessa sensualidade, de carinho, de atenção, se a mulher de casa não nota ele vai atrás de outras.

Este depoimento, somado à premissa apresentada pelo sedutor Marcelo de que "é aquela coisa né, quem não dá assistência abre a concorrência, o maridão fica só no papai e mamãe, fuck fuck e apagou; gozou, deita para o lado e dorme", configuram dados que reiteram resultados de pesquisas desenvolvidas com casais heterossexuais na França e na Finlândia, apontando para a redução do "repertório das técnicas sexuais utilizadas pelos parceiros [...] com o tempo, reduzindo-se também a comunicação entre eles durante as relações sexuais - sobretudo no caso dos homens" (Bozon, 2004a: 133).

No que concerne à diversificação das experiências sexuais entre os/as jovens brasileiros, "a conjugalidade influi diferencialmente para homens e mulheres: em geral, para estas últimas adquirem o significado de um estreitamento do campo de possibilidades em relação às solteiras" (Heilborn, Cabral e Bozon, 2006: 252). Estes autores traçam um paralelo entre "uma modalidade restrita (apenas intercurso vaginal) e uma ampliada (intercurso vaginal e oral ou intercurso vaginal, oral e anal)" no que concerne às técnicas sexuais, e o "repertório ampliado caracterizado por maior intercambialidade entre parceiros e pela possibilidade de uma conduta sexual mais ativa por parte das mulheres" (ibid.: 251), sendo que, "quando as relações sexuais não se dão com o/a parceiro/a atual, apresentam uma maior diversificação" (ibid.: 258).

Andréa Fachel Leal (2005), ao correlacionar os diferentes tipos de práticas heterossexuais e a vivência de uma união afetiva, constatou que a experiência de conjugalidade entre os/as jovens está associada ao exercício do que é qualificado como "básico" no sexo: o coito com penetração vaginal, forma majoritária de interação sexual no contexto da aliança matrimonial. Os dados aqui expostos trazem semelhanças entre os universos juvenil e adulto em relação a este aspecto e ilustram como "a síntese entre atividade sexual, laço afetivo e relação conjugal tornou-se problemática, em particular no contexto de autonomia pessoal crescente das mulheres" (Bozon, 2004b: 88). Reitera-se o pressuposto de que "o ato sexual não é uma prática autonomizada, está sempre inscrita em um conjunto mais amplo de significações, que agrupam desde o contexto relacional específico e o momento da trajetória de vida até o tipo de parceria e afetos envolvidos" (Heilborn, Cabral e Bozon, 2006: 237). 
A frequentadora Simone, que é casada, ilustra tanto o relato de Adriana quanto a hipótese de Luciano, ao justificar perante o marido sua ausência de casa nas noites de terça-feira, quando costuma comparecer ao CM na companhia da amiga Luciana, mediante a desculpa de uma "reunião espiritual". Segundo ela, "senão não dá, não aguenta o casamento, aquilo ali” (faz um gesto com movimentos circulares repetitivos, que traduz rotina). Ela acrescentou: "Hoje é o dia que dá para beijar uns trinta aqui se tu quiser, os homens atacam, te dão a metade da tua idade, isso faz um bem para o ego!"’ . Deste modo Simone consegue tirar proveito de duas situaçóes fortalecedoras de sua autoestima: o assédio e os elogios acionados pelos rapazes na tentativa de conquistar sua adesão à proposta de manter relações sexuais, bem como a "confortável" condição de casada, que lhe confere algum status em relação às mulheres que não têm um companheiro. Este expediente figura como coadjuvante na manutenção de seu casamento, ao contrário de ameaçá-lo, uma vez que "a fantasia da traição [...] abranda nossas carências e insatisfaçōes, sem que, no entanto, nos arrisquemos a romper com o casamento ou mesmo nos comprometamos com o pseudoamante, porque imaterial, inofensivo" (Tavares, 2002: 143). Como disse a promoter Mirian, "elas vêm para cá não porque querem acabar com o casamento, mas para chifrar mesmo, já que tomam chifre; é vingança!". Noutra noite Simone relatou, orgulhosa:

Semana passada eu fiquei com um deus, com um músculo desse tamanho [sinaliza o bíceps], uma tatuagem enorme no braço, era chefe de cozinha, leonino. Entrou numas de que queria me levar para um motel a pé! E lá eu sou de ir a motel a pé? Ele disse que ia ali e voltava logo pra gente sair, e eu sumi! Mas beijei ele muito, também... não deu, né? [para resistir] (Riu).

A fronteira entre o rechaço à abordagem masculina e a permissividade nestes contatos é bastante permeável, composta por variáveis que vão além do estado civil da mulher e passam pelo seu interesse momentâneo e por seus atributos valorativos, aqui marcadamente dependentes da idade, como revelou a jovem $\mathrm{Pa}$ trícia: "Para os homens aqui o que vier é lucro, caiu na rede é peixe, e as mulheres mais velhas dão mais abertura, então se bobear e eu der uma volta com ela [Vera, de cerca de cinquenta anos] por aí, vão chegar mais nela do que em mim, porque ela dá mais abertura, e eu já chego tipo 'me solta', nem olho".

Maria Luiza Heilborn (2006) elenca alguns marcadores que "delimitam o campo de possibilidades dos indivíduos: origem e classe social, história familiar, etapa do ciclo de vida em que se encontram, as relações de gênero estatuídas no universo em que habitam" (Heilborn, 2006: 39). Goldenberg (2006) aponta para 
as severas restrições que atingem as mulheres quando saem da juventude e perdem poder de sedução no jogo da conquista travado no mercado erótico carioca (e brasileiro $)^{9}$. A maior disponibilidade atribuída às mais velhas pode ser explicada pelo fato de elas terem possibilidades muito reduzidas de conquistar um parceiro sexual e/ou afetivo neste campo, implacavelmente regido por variáveis como idade, beleza e poder aquisitivo, restando-lhes quatro opçôes, segundo a autora: a solidão, a relação com outra mulher, ser amante de um homem casado ou buscar indivíduos mais jovens e de classes sociais inferiores. No CM elas encontram meios de realizar as duas últimas alternativas, satisfazendo - ainda que parcialmente - o desejo de compartilhar experiências eróticas.

No que concerne ao aspecto etário, a festa acolhe todos e todas, como mostra o comentário do fotógrafo Gabriel acerca da comemoração do aniversário de uma senhora de setenta anos, que teve espaço ali. A diferença de idade implicada na configuração de alguns casais foi apontada por Marília: "um amigo do Adriano, o Lucas, de dezoito anos, 'ficou' com uma mulher de uns cinquenta anos". A sociabilidade intergeracional tem limites. Os homens mais jovens e/ou de classe social inferior figuram na condição de parceiros sexuais ocasionais, ou como companheiros na "brincadeira" de serial kissers que permeia o âmbito da festa, mas via de regra não constituem alvo de um investimento afetivo a longo prazo, que implicaria, provavelmente, uma relação de dependência econômica, dado que demonstra como "meio social e biografia se combinam na modelagem das trajetórias afetivo-sexuais" (Heilborn, Cabral e Bozon, 2006: 210). Habitualmente um modo de evitar a intimidade, a "sexualidade episódica" pode também gerar meios de promovê-la, segundo Giddens (1993).

A voracidade com que os/as serial kissers interagem comprova o caráter parcial e compensatório da satisfação advinda destes contatos, pois, "quando se é traído pela qualidade, tende-se a buscar a desforra na quantidade, [...] substituir as parcerias pelas redes [...]. Estar em movimento, antes um privilégio e uma conquista, torna-se uma necessidade” (Bauman, 2004: 13). De acordo com Bauman, estes contatos compõem a "opulência do banquete consumista" (ibid.: 68), pois o que "caracteriza o consumismo não é acumular bens [...], mas usá-los e descartá-los em seguida a fim de abrir espaço para outros bens e usos" (ibid.: 67), segundo critérios de novidade, variedade e velocidade. Como disse a assídua frequentadora Teresa, de cinquenta e três anos, “a fila é grande e tem que andar!”.

Os dados aqui expostos ratificam a afirmação de Michel Bozon (2002, 2003) de que a principal transformação nas condiçôes de exercício da sexualidade na segunda metade do século XX consiste no prolongamento da vida sexual, fenômeno mais acentuado para as mulheres do que para os homens. Este "novo calen- 
dário da vida sexual" (Bozon, 2003: 137) ampliou substancialmente a trajetória sexual feminina, até há pouco restrita à esfera matrimonial e à idade fértil. Tal alteração não é apenas quantitativa - em termos de alongamento temporal -, mas aparece também nas atitudes mais ativas e hedonistas de parte destas mulheres (Bozon, 2002). Esta mudança encontra ainda resistências no sentido de sua plena aceitação social, visíveis na acusação de "velha assanhada" que permeia o repertório de julgamentos de valor a que foram submetidas as informantes do estudo sobre gênero, envelhecimento e sociabilidade de Andréa Moraes Alves (2004). No $\mathrm{CM}$, uma frequentadora teceu o seguinte comentário acerca de outra que estava no palco: "As mulheres são mais bagunceiras que os homens. E ela é uma senhora!" (ênfase da informante).

Se antes vigoravam restrições à vivência da sexualidade, agora "entramos em uma sociedade onde impera a obrigação difusa e implícita de nunca interromper nem encerrar de vez a atividade sexual [...], seja qual for nosso estado de saúde, nossa idade, nosso status conjugal" (Bozon, 2004a: 122). Desejar e manter relações sexuais passa de um direito de alguns a um dever de (quase) todos: "a nova obrigação imperiosa de viver nossa vida sexual como um compromisso livre" (Bozon, 2004a: 150, grifos nossos). A regra imposta pela modernidade é paradoxal: "amorlivre obrigatório" (Moraes \& Lapeiz, 1985: 47).

\section{CONSIDERAÇÕES FINAIS}

Os dados reiteram "a contradição entre a permanência de valores tradicionais, como estabilidade, segurança, fidelidade, e outros considerados modernos, como experimentação, privacidade, autonomia, independência" (Goldenberg, 2006: 132), aspectos apontados também em Matos (2000) e Tavares (2002). Goldenberg sinaliza o contraste, observado na cultura brasileira, entre o valor da fidelidade conjugal e os expressivos índices de infidelidade, ao que denomina de "fidelidade paradoxal" (Goldenberg, 2006: 234). Uma fidelidade ilusória: apesar da alta probabilidade de que o/a parceiro/a seja ou tenha sido infiel, deseja-se acreditar no contrário.

Numa época em que impera a ausência de modelos balizadores e a pluralidade de alternativas nos relacionamentos entre homens e mulheres, "Eros e civilização ensaiam um novo bailado, cujas evoluções ainda transparecem descompasso" (Tavares, 2002: 206) e tendem à inversão da fórmula freudiana de troca da "segurança”, adquirida mediante "repressão contínua e vigiada das pulsões, pelo exercício mais fluido, pleno e feliz da experiência erótica (e também conjugal). Felicidade e segurança não precisam se contradizer, excluir, opor", afirma Matos (2000: 
285), reiterando o posicionamento de Bauman (2004). Segundo o autor, "em nosso mundo de furiosa 'individualização', os relacionamentos são bênçãos ambíguas. Oscilam entre o sonho e o pesadelo [...]. Na maior parte do tempo, esses dois avatares coabitam - embora em diferentes níveis de consciência" (Bauman, 2004: 8). Somos todos atores sociais em busca de pontos de equilíbrio entre o "eu" e o "nós", síntese regida por uma lógica interna, pessoal, circunstancial e multideterminada.

\section{REFERÊNCIAS BIBLIOGRÁFICAS}

Alves, A. M. (2004). A dama e o cavalheiro: um estudo antropológico sobre envelhecimento, gênero e sociabilidade. Rio de Janeiro: Editora FGV.

Arent, M. (2007). Gênero e erotismo: etnografia de um Clube de Mulheres no Rio de Janeiro. Tese de Doutorado. Curso de Pós-graduação em Saúde Coletiva, Instituto de Medicina Social, Universidade do Estado do Rio de Janeiro, Rio de Janeiro, RJ.

Bauman, Z. (2004). Amor líquido: sobre a fragilidade dos laços humanos. Rio de Janeiro: Jorge Zahar.

Bozon, M. (2002). Sexualité et genre. Em Laufer, J. \& Maruani, M. (orgs.). MasculinFéminin: questions pour les sciences de l'homme (pp. 169-186). França: PUF. . (2003). Sexualidade e conjugalidade: a redefinição das relaçōes de gênero na França contemporânea. Cadernos Pagu, 20, 131-156.

- (2004a). A nova normatividade das condutas sexuais ou a dificuldade de dar coerência às experiências íntimas. Em Heilborn, M. L. (org.). Família e sexualidade (pp. 119-153). Rio de Janeiro: Editora FGV.

. (2004b). Sociologia da sexualidade. Rio de Janeiro: Editora FGV.

Cecchetto, F. R. (2004). Violência e estilos de masculinidade. Rio de Janeiro: Editora da Fundação Getúlio Vargas.

DaMatta, R. A. (1980). Carnavais, malandros e heróis: para uma sociologia do dilema brasileiro. Rio de Janeiro: Zahar.

Duarte, L. F. D. (2006). A percepção sociológica de assuntos íntimos em grandes números. Em Heilborn, M. L.; Aquino, E. M. L.; Bozon, M. \& Knauth, D. R. (orgs.). O aprendizado da sexualidade: reprodução e trajetórias sociais de jovens brasileiros (pp. 1926). Rio de Janeiro: Garamond e Fiocruz.

Giddens, A. (1993). A transformação da intimidade: sexualidade, amor e erotismo nas sociedades modernas. São Paulo: Unesp.

Goldenberg, M. (2006). Infiel: notas de uma antropóloga. Rio de Janeiro: Record. 
Heilborn, M. L. (2004). Dois é par: gênero e identidade sexual em contexto igualitário. Rio de Janeiro: Garamond.

. (2006). Experiência da sexualidade, reprodução e trajetórias biográficas juvenis. Em Heilborn, M. L.; Aquino, E. M. L.; Bozon, M. \& Knauth, D. R. (orgs.). O aprendizado da sexualidade: reprodução e trajetórias sociais de jovens brasileiros (pp. 2959). Rio de Janeiro: Garamond e Fiocruz.

Heilborn, M. L.; Cabral, C. S. \& Bozon, M. (2006). Valores sobre sexualidade e elenco de práticas: tensões entre modernização diferencial e lógicas tradicionais. Em Heilborn, M. L.; Aquino, E. M. L.; Bozon, M. \& Knauth, D. R. (orgs.). O aprendizado da sexualidade: reprodução e trajetórias sociais de jovens brasileiros (pp. 207-266). Rio de Janeiro: Garamond e Fiocruz.

Leal, A. F. (2005). Práticas sexuais no contexto da conjugalidade: o que implica a intimidade? Em Heilborn, M. L.; Aquino, E. M. L.; Bozon, M. \& Knauth, D. R. (orgs.). Sexualidade, familia e ethos religioso (pp. 61-85). Rio de Janeiro: Garamond e Fiocruz.

Matos, M. (2000). Reinvençôes do vínculo amoroso: cultura e identidade de gênero na modernidade tardia. Belo Horizonte: Ed. UFMG; Rio de Janeiro: IUPERJ.

Moraes, E. R. \& Lapeiz, S. M. (1985). O que é pornografia. São Paulo: Brasiliense.

Tavares, M. (2002). "Pelas lentes do amor": um estudo sobre o cotidiano amoroso de camadas médias urbanas. Aracaju: Remar.

\section{NoTAS}

1 Considerável parte da literatura apresenta as mudanças e transformações entre os gêneros como as mais representativas do último século (Matos, 2000).

2 A opção por denominar esta festa como "Clube das Mulheres" configura uma alusão genérica a este tipo de empreendimento, embora esteja ciente da existência de um clube homônimo na cidade de São Paulo (www.clubedasmulheres.com.br). Foram alterados também os nomes de todos/as informantes, mediante atribuição de codinomes.

3 Giddens traz o conceito de autonomia como "a capacidade de autorreflexão e autodeterminação dos indivíduos" (Giddens, 1993: 202), sendo que, "no terreno da vida pessoal, autonomia significa a realização bem-sucedida do projeto reflexivo do eu - a condição de se relacionar com outras pessoas de um modo igualitário" (ibid.: 206).

4 "A definição dos limites pessoais é considerada fundamental para um relacionamento nãoviciado", segundo Giddens (1993: 106), porém "a revelação para o outro [...] é uma aspiração obrigatória da interação democraticamente ordenada" (ibid.: 208).

5 As “correlações inevitáveis (ainda que não lineares) entre 'escolaridade', 'discursividade', 
'problematização' e 'reflexividade” são também apontadas em Duarte (2006: 22). Já segundo Giddens (1993), "hoje em dia, o eu é para todos um projeto reflexivo - uma interrogação contínua do passado, do presente e do futuro" (Giddens, 1993: 41; grifos nossos).

6 De acordo com Cecchetto (2004), a trilha musical calcada nas "montagens" é característica do estilo funk, no qual novos refrões são adaptados a bases melódicas praticamente iguais, como consta na réplica supracitada.

7 Pesquisa desenvolvida por Márcia Tavares, em Aracaju (SE), revela a trajetória dual da infidelidade para homens e mulheres, sendo delegado a eles o direito de trair e a elas o "dever de aceitar e perdoar a traição masculina, e jamais trair o parceiro" (Tavares, 2002: 144).

8 A infidelidade conjugal enquanto estratégia de incremento da autoestima é apontada por Goldenberg (2006) como um importante desencadeador da traição feminina.

9 Bozon (2002) apresenta dado semelhante no contexto francês.

Recebido em 11 de fevereiro de 2008 Aceito para publicação em 21 de julho de 2008 